\title{
Challenges of treating chronic pain contributing to burnout in primary care
}

\author{
口 Cite as: CMAJ 2019 July 22;191:E:822-3. doi: 10.1503/cmaj.109-5774
}

Posted on cmajnews.com on July 3, 2019.

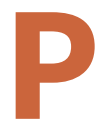

rimary care providers who treat patients with chronic pain appear to be exhibiting signs of burnout, in large part because they often feel unable to help patients overcome their complex challenges.

This was a conclusion of the authors of a recent paper in PLOS ONE based on interviews with 19 doctors and 8 nurses in primary care, supplemented with 40 hours of observations. "Their narratives suggested experiences of depersonalization, loss of job satisfaction and emotional exhaustion in relation to providing care for these patients, key dimensions of burnout," concluded the authors.

Fiona Webster, lead author and associate professor at the Arthur Labatt Family School of Nursing at Western University, said the study didn't set out to explore burnout, but symptoms and indicators for burnout emerged so frequently that the topic became a central part of the paper.

"We were hearing over and over again so many instances of depersonalization" she said. Physicians also described "emotional dissatisfaction and fatigue" and "lying awake at night worrying, feeling they don't know whether a patient is drug seeking or not."

Many felt stuck weighing the risks of prescribing opioids and were concerned about regulatory sanctions. "What an awful position to be in, worrying about not providing pain relief for your patients but also worrying you could potentially kill them," said Webster.

Dr. Abhimanyu Sud, director of the Safe Opioid Prescribing program at the University of Toronto, said he's concerned by the common experiences of emotional fatigue and depersonalization among health professionals working in

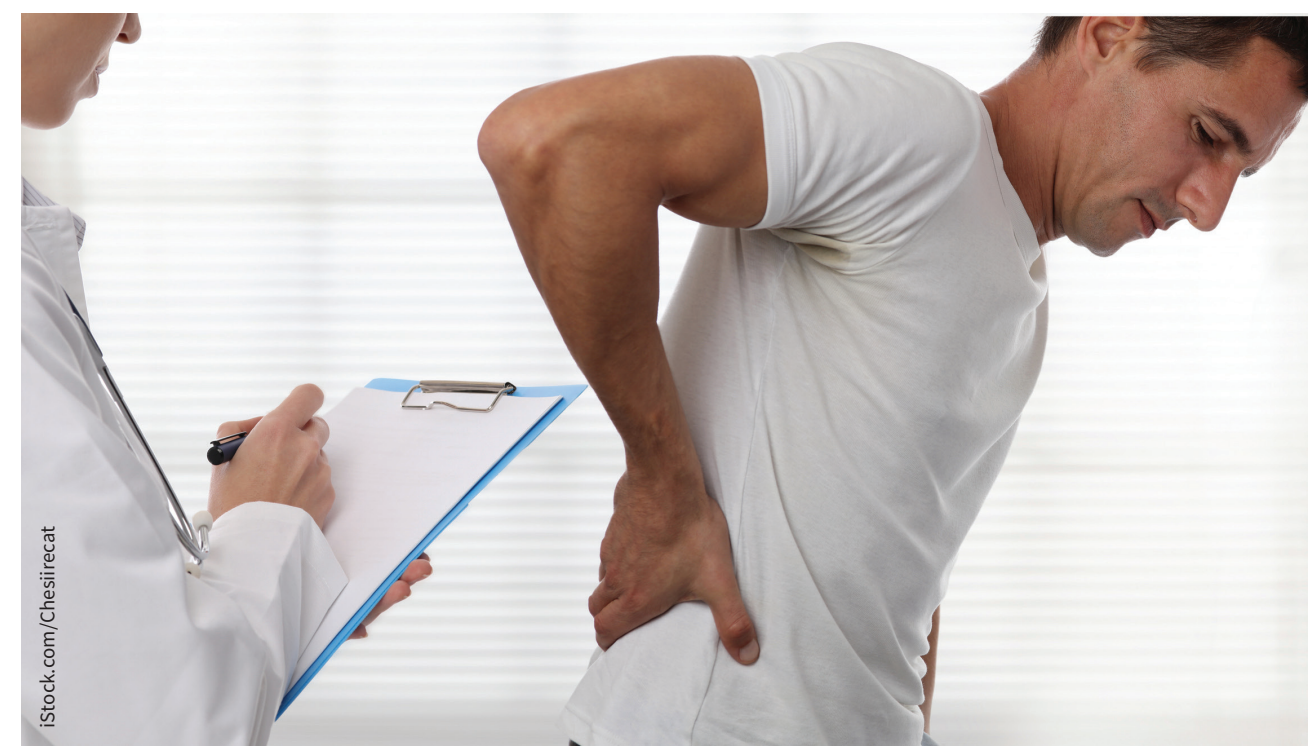

Many primary care workers feel unable to help patients with complex chronic pain problems.

chronic pain. "My biggest concern is how that ends up playing out in clinical encounters," he said. "If you are burnt out, it can be very hard to be an advocate for your patients, especially the patients who are potentially in the most need."

In Sud's view, providers should be "reluctant to start someone with chronic pain on opioids for a wide variety of reasons," including that the evidence now shows opioids are "not very effective for chronic pain." What's trickier is patients with chronic pain who have been using opioids for a long time. "If that fear of a regulatory sanction turns into 'I'm going to abruptly discontinue or rapidly taper your opioids,' that's going to precipitate withdrawal ... which is extraordinarily uncomfortable and people may seek their opioids elsewhere, and we have very easy access to street opioids whose potency is not known."

Meanwhile, Sud pointed out, alternatives like physiotherapy, meditation and cognitive behavioural therapy have evidence behind them for the treatment of chronic pain, but they're not funded or difficult for patients to access. "The big irony is that we purport to be evidencebased, but in reality, what we can offer is not guided by evidence."

Dr. Rupa Patel, who treats patients with chronic pain at Kingston Community Health Centres and is the women's health program director at Queen's University, thinks physicians often aren't proactive enough about seeking out alternatives, because of a "defeatist mindset." She pointed out that several online resources can help. One she recommends to her patients is a website that offers yoga routines for various kinds of back pain.

Another of Patel's concerns is that many physicians who treat chronic pain experience "counter transference," where patients' feelings of helplessness are transferred to providers, and that can 
further exacerbate burnout. "I think there's a lot of counter-transference prescribing going on because physicians think, 'I need to do something."'

Recognizing that past experiences with trauma often play into chronic pain and addiction, the training of physicians in trauma-informed care could improve their job satisfaction, according to Patel. "Many of these patients have had signifi- cant adversity in childhood and they tell you things maybe that they never told you before, and that's such a privilege... it brings more meaning to your interaction with them," she said. "You can make connections for them as adults and really help people move forward in their lives."

Webster agrees that the chronic pain and addiction epidemic reveals limits in medical training. "Medical education needs to focus more on the social and structural determinants of health," she said.

"With so many patients with chronic pain, problems are not strictly medical; they're also social," added Webster. "We need more intersectoral collaboration when we're designing clinical interventions."

Wendy Glauser, Toronto, Ont. 